\title{
The Internet: Changing the Way Horticulturists Communicate
}

Tim Rhodus ${ }^{1}$ and J ames H oskins²

\begin{abstract}
Summary. This article examines opportunities for enhanced information access and dissemination available to professional horticulturists using the I nternet. The intent, however, is not to provide a comprehensive cataloging of where and how to find various databases or sources for multimedia educational resources. While some of these resources are reviewed, the goals of this article are to provide a background of the Internet environment and to examine the communication impacts of the I nternet on horticultural researchers and educators. 0 ur view is that computer-aided communication is an opportunity challenge, which should be confronted by individual horticulturists and the discipline as a whole. Examples of these new resources that can have a positive impact on the accomplishment of work responsibilities of horticultural professionals are discussed.
\end{abstract}

Additional index words. world wide web, electronic publishing

$\mathrm{n}$ the traditional model of scholarly research, scholars engage in a process of generating and disseminating information. This traditional model of scholarly activity can be characterized by a professor who conducts original experimentation or inquiry, either alone or in collaboration with peers, and then publishes findings in a scientific journal. $\mathrm{H}$ aving passed the process of peer review, journal articles imply an endorsement of professional quality and serve to inform others of current developments in the field. R esearch results also are presented live at scientific meetings, an activity that provides wider audiences within the discipline an opportunity for interaction, evaluation, and feedback. Scrutiny of one's research by peers can initiate a process of reflection and refinement which leads to further investigation and generation of additional data. U Itimately, research occurs as a dynamic cycle of information dissemination and acquisition.

While the traditional model is focused primarily on information dissemination among peers, there are also implicit responsibilities to further disseminate information to the general public and commercial operators through teaching, extension, programs of professional societies, and popular media publications.

\footnotetext{
${ }^{1} \mathrm{~A}$ ssociatepr ofessor, D epartment of $\mathrm{H}$ orticultureand C rop Scienceand D epartment of A gricultural Economics, TheO hi oStateU niversity, $\mathrm{H}$ owlett $\mathrm{H}$ all, 2001 Fyffe Court, Columbus, OH 43210.

${ }^{2} \mathrm{R}$ esearch assistant, D epartment of $\mathrm{H}$ orticulture and C rop Science, The Ohi o State U niversity.

Salariesand research support provided by stateand federal fundsappropriated to theO hi oA gri cultural $R$ esearch and D evel opment C enter, The Ohio State U niversity. M anuscript no. 50-95.

The cost of publishing thispaper wasdefrayed in part by thepayment of pagecharges $U$ nder postal regulations, thispaper ther eforemust be her eby marked advertisement solely to indicate this fact.
} 
$\mathrm{H}$ ortT echnol ogy is an example of a publication in which researchers place results before a specialized general public. Frequently, the responsibility of information dissemination to thegeneral public is removed from the individual scholar and placed with professional editors and writers who work in extension or on the staffs of journal publications.

\section{Enhancing the traditional model}

The central issue to address is whether the traditional model of scholarly research and its methods of information acquisition and dissemination needs to be examined for weaknesses in light of recent developmentsin telecommunicationstechnology. Framing this question more affirmatively, does computeraided communication present opportunities for improvement of the traditional model? Answering this question calls for a review of the current state of computer use by horticulturists and a brief overview of the Internet computing environment.

Rapid communication al ways has been a key requirement and a fundamental characteristic of scientific research (Schatz and $\mathrm{H}$ ardin, 1994). M any horticultural professionals, therefore, have accepted readily and begun to use currently available computer technologies linked to the I nternet to facilitate this disciplinary requirement. Colleges and universities offer local area networks where, for example, library collections are computerized and searchable, usually from one's personal office computer. Library information systems invariably offer access to databases organized along broad disciplinary categories, which enable searches of journals, dissertations, and print media titles. Electronic mail isbeginning to beused commonly for communicating routine information throughout the immediate office environment. O nce the e-mail habit is established, increased communication with colleagues at other institutions soon follows. Expanding on the one-to-one nature of e-mail, e-mail lists link scholars having common interests in specialized topics and enable them to communicate simultaneously their latest discoveries to everyone in the group. $M$ any of these e-mail lists, of which there are hundreds, are announced publicly, but smaller groupssometimes form their own lists to maintain privacy among a select group of colleagues working in a common area.

To facilitate the collaborative development of manuscripts among geographically dispersed scholars, many increasingly areturning to electronic file transfer. This capability enables spreadsheet and word-processing documents and other digitized media, such as electrophoretic protein gels, to be transferred, worked on, or analyzed when re- ceived, thus eliminating delays in physically transmitting documents via the mail. This explosion in electronic communication alternatives removes barriers to collaboration among geographically separated researchers and increases opportunities to access remote information from digital libraries and databases (Grimshaw, 1994).

While information acquisition is one of the principle ben efits offered by the Internet environment, many educators may have avoided using I nternet resources beyond basic services such ase-mail and library database searches because of the perception that the environment is too amorphous, consisting primarily of frivolous, trivial, extraneous, and difficult-to-accessinformation. With so much out there, being able to find information of value and relevance to one's work has been a significant weakness of the Internet. Technological solutions, however, are arriving in response to this critical need, and the cryptic technicalities of many aspects of I nternet use are declining (H ewson, 1994). The Internet is progressing rapidly toward a more seamless environment, in which the wealth of Internet-based information is presented as "the illusion of a single, very powerful computer, rather than a collection of disparate machines" (Grimshaw, 1994). These technical improvements have moved the I nternet away from the esoteric tool it traditionally has been and opened its resources to whole new communities of users (Schatz and $\mathrm{H}$ ardin, 1994).

\section{Origins of the Internet}

Thel nternet originated during the 1960s under the direction of the U.S. Dept. of Defense (USDOD) Advanced Research Projects Agency. This initial network, ARPANET, linked the Pentagon with computers at the U niv. of California-L os Angeles, Stanford Research Institute, U niv. of California-Santa Barbara, and the U niv. of $U$ tah. ARPANET was designed as a means of decentralizing U SD O D computing resources in the event of a nuclear attack. By 1971, there were 15 sites connected, but the initial military goal of the network was being replaced with the more scientific goal of networked information exchange (ARPANET was eliminated in 1990). By 1984, the number of host computers surpassed 1000 , and in 1986, involvement by the $\mathrm{N}$ ational Science Foundation (N SF) sparked events that would result in the present configuration of the Internet. U nder N SF coordination, linkage of thousands of universities occurred rapidly, starting first within the U nited States and soon after throughout the world. The number of I nternet hosts (a host is an individual computer linked to the Internet) surpassed $1,000,000$ in 1992 , totaled 6.6 million by 


\section{"Powerful WWW search toolsare being developed and new releases become available by the month"}

July of 1995, and has been predicted to reach 101 million by the end of the century (T reese, 1995).

\section{Gopher software}

A pivotal advance in information acquisition and dissemination via the Internet occurred in 1991 with the release of Gopher software by the U niv. of M innesota. Before Gopher, accessing information generally required mastery of complicated operating commands to log into a remote host computer, whereupon one literally would have to root around through confusing layers of cryptically named file directories. For this reason, Internet users were primarily computer-science and other computer-based professionals. U sing Gopher, novice users could move quickly between layers of descriptively titled information categories with simple text-oriented interfacesor point-and-click commands. This development quickly opened up the Internet to many more scholars outside of computer-science disciplines.

Associated with the release of Gopher was the development of sophisticated tools that permitted keyword searches of I nternet G opher servers. For example, using a $G$ opher search tool such as Veronica and entering the word horticulture would return a listing of world-wide G opher sites where the term horticulture figures as a part of the descriptive title of a specific informational resource. The information resources could range from descriptive plant lists, information about educational programs in horticulture, to extension fact sheets. Gopher continues to bean important I nternet resource to day, with over 7000 Gopher servers on the Internet (Schatz and $H$ ardin, 1994). In 1993, the annual growth rate of $\mathrm{G}$ opher traffic on the Internet was 997\% H owever, in just 3 years, Gopher has been supplanted by newer information retrieval tools. As one observer noted: "In the current tremendous expansion of the $\mathrm{N}$ et we have the opportunity to watch and study the growth of a fantastically huge new industry, on a scale similar to the building of the public highway systems, postal systems, telephone, railroad, and electrical infrastructure" ( $\mathrm{H}$ ardy, 1993).

\section{The World Wide Web and browser programs}

In 1989, 2 years before the release of Gopher, an initiative was launched by researchers at the European Laboratory for Particle Physics (CERN) in G eneva, Switzerland, called the World Wide Web (WWW) project. The WWW was developed originally to allow information sharing within internationally dispersed teams and enhance the dissemination of information by support groups. $O$ riginally aimed at the high-energy physics community, it attracted much interest and spread to other areas ( $M C L$ aurin, 1995). Basically, the WWW consists of thousands of information resources located on a wide variety of computer systems and interconnected through hypertext links. Thelinks, embedded within the body of the information being presented, contain computer addresses that connect one piece of information directly to another regardless of physical location. The resulting environment facilitates information dissemination of logically related subject matter in such a way that the user can navigate among many different network systems following a series of hypertext links. TheWWW embodiestheidea of "worldwide information space" (Schatz and H ardin, 1994) or seamless "enterprise-wide computing" (Grimshaw, 1994). The user is able to access information without the burden of technical considerations and irrespective of the location of the information in physical space. The end result is that the entire world of available Internet information resources existsasastreamlined total information space.

The CER N group began to release what are called browser programs during the early 1990s. Whereas with Gopher a user moves back and forth through hierarchical collections of information and ultimately arrives at a document that is the effective dead-end of that information search, the WWW and its hypertext links create a potentially continuous environment of interlinked information resources. The hypertext/ hypermedia environment made simple access to multimedia resources including text, sound, movies, and photos. Currently, the most widely used browser program is $\mathrm{N}$ etscape. $\mathrm{N}$ etscape has surpassed M osaic-the first sophisticated browser program developed in 1993 at the $U$ niv. of Illinois $\mathrm{N}$ ational Center for Supercomputing Applications (NCSA)-in acceptance and popularity due to the enhanced graphical features and ease of use it offers. During 1994, use of all browser programs grew $11 \%$ each week, and use doubled every 6 weeks (C rawley, 1994). N etscape and N CSA's M osaic are freely distributed on the Internet to all academic users. Commercial Internet providers, such as Prodigy, Compuserve, and America $\mathrm{O} L$ ine, offer their own in-house I nternet browsers.

\section{From browsing to software agents}

Powerful WWW search tools are being develo ped and new releases become available by the month. Some of these software agents have names such as Web spiders, wanderers, 
crawlers, and snakes (Zakon, 1995). These agent programs are designed to search autonomously the Internet and locate information based on user-supplied search terms (Waldrop, 1994). At present, autonomous agent searches are feasible only for key words found in Web-server documents names and titles, for limited searches of document page content, or to find servers located within specified geographical areas. In the future, computing advances will occur that will permit greater specificity to information acquisition. $M$ any of these advances, however, will require greater computing power than presently available and advances in bundling data traveling on the Internet. While N etscape and $M$ osaic represent the present end-point advance in an on-going process, future development will bring greater power in information dissemination and acquisition capabilities. I deally, scholars will be able to enter a string of very specific search terms and have a software agent return customized information through a process termed interactive analysis (Schatz and $\mathrm{H}$ ardin, 1994). For example, one could query thel nternet for " journal articles, greenhouse production, roses, nutrition, after 1992" and receive immediate access to extant full-text articles, with accompanying tables, graphs, and photographs. The $\mathrm{N}$ ational Science Foundation, the Advanced Research Projects Agency, and the $\mathrm{N}$ ational Aeronautics and Space Administration recently have funded a 4-year $\$ 24.4$ million effort in partnership with a consortium of leading universities and private sector corporations to develop systems for collecting, organizing, and storing digital information. These and other efforts will make a greater range of information more readily availableto groups as varied as elementary school studentsand research scientists (Waldrop, 1994).

Interest in and access to the I nternet also isoccurring in the general population. Scarcely a day goes by without a popular media referenceto the Internet, or theso-called information superhighway. During 1993, business and media began to take notice of the I nternet (Zakon, 1995). The most basic I nternet service, e-mail, has become a defacto requirement for progressive business people. Estimates place the number having electronic mail capability at 25 million, with expectations that another 25 million people, primarily from business, will be linked to the I nternet within the very near future (L ewis, 1994). A growing number of communities throughout the U nited States offer basic Internet services through community free-nets, frequently administered through the public library system on terms similar in ease to signing up for a library card. Public access to Web servers, while not as available as e-mail, is increasing. There is also growing public perception that more of the information the public desires, the questions they have, or the problems they wish to resolve have I nternetbased solutions. For example, during a 2week period in July 1994, 1.4 million users visited a WWW server offered by N ASA's s et Propulsion Laboratory to view images and movies of Comet Shoemaker-L evy's impact with theplanet] upiter (http:/ / www.jpl.gov/ sl9/ s19.html). By September 1995, 4.6 million Web browsers had accessed N ASA's information on thecomet. Commutersin southern Californiacan accessfreeway system maps giving immediate readings on traffic flow speeds and can plan their routes home accordingly (http:/ / www.scubed.com/ caltrans/ transnet.html).

\section{Horticultural information resources}

$M$ any useful horticultural resources can be found today on the Internet. A listing of G opher sites can be generated using M osaic/ $\mathrm{N}$ etscape and a search tool called Search Gopher Space (http:/ / galaxy.einet.net/ gopher/ gopher.html). Entering the keyword "horticulture" returns over one hundred "hits," including the following Gopher servers: a) the Virginia T ech H orticulture D ept. which provides monthly news releases; $b$ ) the $\mathrm{U}$ niv. of $\mathrm{M}$ issouri, which provides $\mathrm{H}$ orticulture Guides; c) I owaStateU niv., which offers information on horticulture department curriculum, career opportunities, and faculty; d) $M$ ichigan Stateand Auburn universities, which supply general informational releases on horticultural subjects; e) the U niv. of M innesota, which lists a directory of proposed federal environmental legislation; f) the I sraeli M inistry of Agriculture, which lists research being conducted at the Institute of $\mathrm{H}$ orticulture; and, g) Pennsylvania State U niv., which offers a variety of horticultural information resources. The weakness of $\mathrm{G}$ opher keyword searches, however, is that almost all returned Gopher information istext-only, and the lack of the hypertext links of WWW servers means that the relevance of information cannot always be discerned from file names.

A handful of newly developed Web sites present horticultural and related discipline information. Two of the most comprehensive servers targeted for those interested in applied horticultural information are the Centre for $L$ andscape Research at the $U$ niv. of Toronto (http:/ / www.clr.toronto. edu:1080/ clr.html) and the Australian $\mathrm{N} \mathrm{a-}$ tional Botanic Gardens (http:/ / 155.187.10.12/ index.html). Thestated goal of the Centre for $L$ andscape Research server is to encourage a "collaborative environment

"Future
development
will bring
greater power
in
information
dissemination
and
acquisition
capabilities"




"What is the
likely impact
of I nternet
information
resources on
the
traditional
model of
scholarly
activity?"

for the exploration of ideas relative to the design, planning, and policies of the environment" and "promote the use of electronic mediato foster moreinformed decision-making." The Australian N ational Botanic Gardensserver features activities and programs of the gardens and isstrong in its presentation of photos of Australian flora. A third Web site, the U niv. of Delaware Botanic Gardens (http:/ / bluehen.ags.udel.edu/ udgarden.html), offerstheuser amap of the garden's layout, photographic images, and identification information on selected species.

To date (February, 1996), there are 14 departmentally oriented Web servers associated with programs offering undergraduate and graduate education in horticulture. Each of these serversgenerally provides curriculum information, course-specific information, announcements, research programs, listings or biographies of personnel, and links to other Web sites. These programs and their Web addresses are presented below:

- D epartment of $\mathrm{H}$ orticulture at $\mathrm{Clemson}$ U niv. can be reached at (http:/ / agweb.clemson.edu/ H ort/ HortM ain.htm).

- Dept. of Floriculture and O rnamental $\mathrm{H}$ orticulture of Cornell U niv. can be reached at (http:/ / www.cals. cornell. edu:80/ cals/ dept/ flori).

- D epartment of Agronomy and $\mathrm{H}$ orticulture at $\mathrm{N}$ ew M exico State U niv. can be reached at (http:/ / taipan.nmsu.edu/ aght/ agronomy.html).

- D epartment of Environmental $\mathrm{H}$ orticulture at $\mathrm{U}$ niv. of $\mathrm{C}$ alifornia, $\mathrm{D}$ avis, can be reached at (http:/ / envhort.ucdavis. edu).

- Department of $\mathrm{H}$ orticulture at Texas A\& M U niv. can be reached at (http:/ / aggie-horticulture.tamu.edu/ ).

- D epartment of $\mathrm{H}$ orticulture at the U niv. of Illinois can be reached at (http:/ / gopher.ag.uiuc.edu/ H ort/ H orticulture. H ome.H tml).

- D epartment of H orticultural Science at the U niv. of $\mathrm{M}$ innesota can be reached at (http:/ / www.soils.umn.edu:8003/ ).

- D epartment of $\mathrm{H}$ orticulture at $U$ niv. of N ebraska can be reached at (http:/ / 129.93.226.104).

- D epartment of Plant and Soil Science at the $U$ niv. of D elaware can be reached at (http:/ / bluehen.ags.udel.edu/ homepage/ plsc/ plschome.html).

- Department of H orticulture and Crop Scienceat $\mathrm{O}$ hio StateU niv. can bereached at (http:/ / hortwww-2.ag.ohio-state. edu/ hvp/ H VP1.html).

- H orticulture D ept. at Purdue U niv. can bereached at (http:/ / www.hort. purdue. edu/ hort/ hort.html).

- $\quad H$ orticultural SciencesD ept. at theU niv. of Florida can be reached at (http:/ / gnv.ifas. ufl.edu/ WWW/ AGATOR/ HTM/ HORTICU L.HTM).

- D epartment of $\mathrm{H}$ orticultural Science at $\mathrm{N}$ orth $\mathrm{C}$ arolinaStateU niv. can bereached at (http:/ / www2.ncsu.edu/ ncsu/ cals/ hort_sci/ homehort.html).

- Department of $\mathrm{H}$ orticulture, Forestry and R ecreation R esourcesat KansasState U niv. can be reached at (http:/ / witch.oznet.ksu.edu/ dep/ H FRR).

While these 14 sites provide valuable information on a variety of topics, the full potential of these new information resources will be realized when they begin to develop and offer instructional, research, and outreach programs jointly through their respective servers. Currently, an Internet user can sample information from each server but fail to arrive at a comprehensive view of the discipline of horticulture.

\section{Impacts on the traditional model}

Given thisoverview of the I nternet, what is the likely impact of I nternet information resources on the traditional model of scholarlyactivity? An editorial in Science(B rauman, 1994) noted that "computers and computing have changed the modern world, but the effects on the practice of science have been especially profound." In scientific practice, increased computational power has permitted scientists to explore and analyze more intricate and complicated datasets, leading to greater complexity in the modeling of natural phenomena. These advances, along with access to a richer information matrix, represent, however, only a quantitative progression in the conduct of scientific inquiry. In this view, computers and the Internet are merely tools a scientist uses to enhance the quality of the scientific method of inquiry. The basic attribute of the scientific process, rigorous testing of hypotheses formulated through observations of natural phenomena, remains unchanged. There are nonetheless qualitative impacts on the disciplinary culture and conduct of science specific to $\mathrm{H}$ orticulture.

Four key elements in the discipline of horticulture provide astrong incentive to use the I nternet for computer-aided information acquisition and dissemination, and create a dynamic that will have an impact on the traditional model. First, a strong visual component characterizeshorticultural knowledge and study. Given that knowledge related to plant identification and use is central to the undergraduate horticulture curriculum and that there is no substitute for a high-quality picture, most educators develop one or more slide sets to compliment their teaching programs. H owever, in most cases, when the 
professor changes institutionsor retires these slide resources often are lost. Fortunately, we are now seeing more plant image databases on the Web (example: $\mathrm{H}$ arvard $\mathrm{H}$ erbarium at http:/ / golgi.harvard.edu/ ). Professors are able to pull individual images from these databases and insert them into presentation softwarefor classroom lectures. Alternatively, students can access these same resources out of class for review and self-study.

The second key element that linkshorticulture to the Internet is the technical and practical element contained in the undergraduate curriculum, which, similar to plant identification, requires that students are presented highly visual information. Examples are plant grafting techniques and growth medium preparation. T he W eb environment is very conducive to a type of instruction that is facilitated through the use of self-paced tutorials or lab assignments on subjects requiring step-by-step instructions, accompanied by audio and video clips to explain what is happening. An example of this type of interactive resource that a Web server can provide is the frog dissection tutorial available from the U niv. of Virginia (http:/ / curry.edschool.Virginia.EDU:80/ -insttech/ frog/ ).

The third element linking horticulture to the Internet involves new efficiencies in the communication of information and research results. Research activity within some subdisciplines of horticulture moves so rapidly that scholars' exclusive dependence on the traditional publication cycle of a monthly or quarterlyjournal might prohibit them from keeping up with breaking developments. H orticulturists involved in biotechnology were among the early adopters of Internet communication. Through a commitment to rapid dissemination of research results via the Internet, these scientists are able to perform comparative searches on comprehensive databases and be fairly confident that the latest findings are included. An editorial in Science (Winograd and Zare, 1995) singled out the Journal of Biological Chemistry as an example of an online journal offering valuable features such as full-text articles, search engines to search contents quickly and efficiently for information, and ameansto print desired pagesfor extended examination (http:/ / www-jbc.stanford.edu/ $\mathrm{jbc/}$ ). The editorial noted that, in time, the electronic journal may replace the printed scientific journal and result in accelerated scientific progress. Similarly, in the area of providing information to industry and public clientele groups, use of the Internet to communicate late-breaking information about regulatory issues, environmental conditions, and/ or disease outbreaks will emerge as a valuable disciplinary tool.
The fourth key element that links horticulture to the Internet is the issue of format. For example, researchers involved in electrophoretic gel protein sequencing commonly use digitizing software to render and interpret sequencesmore precisely. Consequently, a traditional photographic rendition of a gel within the pages of a journal article offers less utility, becausethe preferred format for greater accuracy in interpretive analysis is the digital format. These same scholars also rely heavily on Internet-based protein databases such as the U niv. of Geneva's 2-D protein electrophoretic gel database (http:/ / expasy.hcuge. $\mathrm{ch} / \mathrm{ch} 2 \mathrm{~d} / \mathrm{ch} 2 \mathrm{~d}$-top. html). In terms of information dissemination to industry professionals, format possibilities offered by the Internet include image-based maps showing the latest areas of insect or plant disease outbreaks, current soil moisture conditions, and quality of crop development. Each of these information resources, of course, depends on digitized format for their creation and dissemination over the I nternet.

\section{Opportunities for the future}

The Internet, and the associated broad advances in telecommunications and computer software it encompasses, providesscholars with opportunities for strengthening the discipline of horticulture in many ways. The ability to network with colleagues using email and electronic file transfer has brought people, ideas, and information together in a more efficient manner and has enhanced collaborative efforts. As horticulturists develop Web servers to present teaching materials, course syllabi, research results, or late-breaking developments, they will collaborate more frequently with colleagues in other academic disciplines who have gone before them and discovered the pitfalls and challenges of developing information for the Internet. Likewise, discovering that colleagues al ready have developed similar courses and that their materials can be shared and accessed electronically providesmany obvious benefits. Asmore and more secondary schools use instructional computer labs with Internet access, teachers logically will look to universities as sites for discipline-related curriculum materials to present to their students. Finally, continuing education programs and employee development programs will benefit from increased availability of curriculum materials and minicourses developed for specific learning goals. As one observer noted: "Learning can be independent of time and place, and available at all stages of a person's life. The learning context will be technologically rich. L earners will have access not only to a wide range of media, but also to a wide range of sources of education" (Bates, 1993).

"Thereisan
obviousneed
for leadership
to facilitate
the
development
of ectronic
information
resources"




\section{What is needed?}

French sociologist J ean-FrançoisB arbier Bouvet, who studiesthe impact of computers on society, wrote: "if in the past the culture of someone could be defined as the capacity to keep, memorize and recall information, today it should be defined as the capacity to wisely use information; in other words to be able to retrieve the information when it appears necessary" (Bouvet, 1993). In his view, incumbent on the practicing scientist will be recognition of the importance of integrating the intellectual products of scientific inquiry into the world-wide information space of the Internet. As horticulturists generate and disseminate research results within an information-rich environment, using an evolving array of computer-based tools, there will be inevitable impacts on the traditional disciplinary model of scholarly activity, most notably in the area of self-publishing. R esearch scientists who rapidly communicate research results to world-wide communities of peers, and scholars who make their curriculum materials, lecture outlines, lab assignments, and self-paced tutorials available on the I nternet, are in effect self-publishing. $\mathrm{H}$ owever, the I nternet does not transmit merely to students and professional peers. As wider and more diverse groups of knowledge seekers discover the immediate availability of university-generated information, they may ask for more. Given the advantages of timeliness, multimedia-compatibility, and ease of acquisition, horticulturistssoon may be devoting increased amounts of time to electronic-publishing in order to satisfy an ever-growing demand for digital information. Extension professionals or private consultants may become less valued as people who have exclusive access to information, and more valuable as interpreters and synthesizers of information. This evolution toward an increased importance of Internet self-publishing may lead to theirony that the published journal article, thesinequa non of the traditional model of scholarly activity, could becomelesssignificant to many. This suggests that reevaluation and possible redefinition of standards of academic excellence are warranted.

At the same time, there is an obvious need for leadership to facilitate the development of electronic information resources. A coordinated effort, led either by ASH S or horticulturists working in the Internet environment, is needed to assess and record thoroughly the horticultural resources on the Internet. This would minimize duplicative efforts and help give shape to the evolving presence and presentation of the discipline of $\mathrm{H}$ orticulture on the Internet. Integral to this process is development of criteria for peerreview evaluation for the purpose of maintaining professional standards. M uch can be learned from colleagues in other fields that have been even faster to take up electronic publishing. I $\mathrm{fI}$ ternet activity isto beadopted more widely by horticulturists and accepted as a recognized and rewarded scholarly activity, identified standards and definitions of quality will be required.

\section{Literature Cited}

Bouvet, J ean-Francois Barbier. 1992. Lire la page comme un image. In: Alain Bentolila (ed.). Les Entretiens $\mathrm{N}$ athan. Parole, Ecrit. Imag, p. 225239. N athan, Paris.

Brauman, John I., Voss, David F. and Tim A ppenzeller. 1994. Editorial: computing: networks and modeling. Science. Vol. 265, 12 Aug.

Crawley, James 1994. For lucky ones, mosaic offers the world. The San D iego U nion-T ribune, p. 8.5 July.

Grimshaw, Andrew S. 1994. Enterprise-wide computing. Science. Vol. 265, 12 Aug.

$\mathrm{H}$ ardy, $\mathrm{H}$ enry Edward. 1993. The history of the $\mathrm{N}$ et. M S thesis. Grand Valley StateU niv. 28 Sept. e-mail: seraphim@umcc.umich.edu.

H ewson, David. 1994. The wired-up revolution. Sunday Times, London. 26 J une.

Lewis, Peter H . 1994. Getting down to businesson thenet. $\mathrm{N}$ ew York Times. 19 J une. Section 3, p. 1.

McLaurin, A listar. 1994. About the world wide web; history of the world wide web. London Science Museum WWW site: http:/ / www.nmsi.ac.uk/ usage/ histweb.html.

Schatz, Bruce R., and Joseph B. H ardin. 1994. NCSA mosaic and the world wide web: global hypermedia protocols for the internet. Science. Vol. 265, 12 Aug.

Treese, Win. 1995. The internet index. Number 10, 0 ctober 14, 1995. WWW distribution address: http:/ / www.openmarket.com/ diversions/ internet-index/

Waldrop, M . Mitchell. 1994. Culture shock on the networks. Science. Vol. 265, 12 Aug.

Waldrop, M. M itchell. 1994. Software agents prepare to sift the riches of cyberspace. Science. Vol. 265, 12 Aug.

Winograd, Shmuel and Richard N. Zare. 1995. "Wired" science or whither the printed page? Science. Vol. 269, 4 Aug.

Zakon, $\mathrm{R}$ obert $\mathrm{H}$ obbes $\mathrm{H}$ obbes' Internet Timeline, v2.2. WWW distribution address: http:/ / info.isoc. org/ guest/ zakon/ Internet/ H istory/ HIT.html . E-mail: timeline@hobbes.mitre.org. 